This item was submitted to Loughborough's Research Repository by the author.

Items in Figshare are protected by copyright, with all rights reserved, unless otherwise indicated.

\title{
Ability to be active: exploring children's active play in primary schools
}

\section{PLEASE CITE THE PUBLISHED VERSION}

http://dx.doi.org/10.1080/21594937.2015.1060569

\section{PUBLISHER}

(c) Taylor \& Francis

\section{VERSION}

AM (Accepted Manuscript)

\section{PUBLISHER STATEMENT}

This work is made available according to the conditions of the Creative Commons Attribution-NonCommercialNoDerivatives 4.0 International (CC BY-NC-ND 4.0) licence. Full details of this licence are available at: https://creativecommons.org/licenses/by-nc-nd/4.0/

\section{LICENCE}

CC BY-NC-ND 4.0

\section{REPOSITORY RECORD}

Sandford, Rachel A., Rebecca Duncombe, Carolynne L.J. Mason, and Carly W. Butler. 2019. "Ability to Be Active: Exploring Children's Active Play in Primary Schools”. figshare. https://hdl.handle.net/2134/17947. 
To appear in International Journal of Play

\title{
Ability to be active: exploring children's active play in primary schools
}

\author{
Sandford, R., Duncombe, R., Mason, C. \& Butler, C.W. \\ Loughborough University
}

\begin{abstract}
This paper presents findings from an innovative multi-method study which sought to examine the impact of toys and toy substitutes on children's physical activity levels in two UK primary schools. Accelerometers were used to record the physical activity levels of 52 Year 3 pupils (aged 7-8 years) during four separate 30-minute play sessions and, for comparison, during other periods of the school day (breaks, lunch-times and PE lessons). Qualitative data were generated through observations, field notes and semi-structured focus groups with pupils. The findings suggest that a relatively short session of unstructured active play with toys or toy substitutes can make an important contribution to a child's daily level of physical activity. Moreover, they reveal that children's enjoyment of play sessions and their creative, physical and social competence are also important influences on their engagement in, and with active, play. Some implications for policy, practice and future research are discussed.
\end{abstract}

Key words: active play, physical activity, primary school, toys, competence

Word Count: 7780 (Main text and references)

\section{Ability to be Active: Exploring children's active play in primary schools}

\section{Introduction}

The contribution of play to the development of young children's social and emotional development is well documented (e.g. Burdette \& Whitaker, 2005; British Toy and Hobby Association, 2011). The contribution of play to children's levels of physical activity, however, has been subjected to somewhat less scrutiny. This paper reports findings from an innovative multi-method study, undertaken in the UK, which was aimed at developing a deeper understanding of the relationship between children's play and their physical activity (PA) levels. The study itself can be seen to build on research findings which have suggested that active play can make a potentially useful contribution to children's levels of physical activity (Brockman, Jago \& Fox, 2010) and that children are more likely to engage in activities they deem to be 'fun' (Hemming, 2007) and be more active when given a choice of toys to play with (Feda, Lambiase, McCarthy, Barkley \& Roemmich, 2011). Moreover, it can be seen to reflect rising apprehension, within the UK and beyond, in the apparent decline in children's play (e.g. Gray, 2011) and the potential implications this holds for young people's health, development and well-being (e.g. Fairclough, Butchers \& Stratton, 2008). In the British context, for example, while unstructured play is acknowledged as being a means through which young children can potentially meet daily physical activity recommendations, there are growing concerns that children are perhaps not engaging in enough generic physical activity or physically active play (Department of Health, 2011). 
The following discussion examines some of these issues, beginning with an overview of relevant literature relating to young people's engagement with physically active play, the perceived decline of physically active play (particularly within the school context) and the potential implications of this for children's health, development and general well-being. This is followed by an explanation of the specific study, before core findings from the research are presented and discussed. It is worth highlighting at this point that the purpose of the study was twofold: firstly, to quantitatively examine the impact of toys and toys substitutes on children's PA levels and, secondly, to qualitatively explore the nature of children's social and physical interactions within play sessions. Although some reference is made to both aspects of the study, the focus in this paper is on the second aim i.e. the qualitative data exploring children's enjoyment of the play sessions and their physical, social and creative competence during active play.

\section{The benefits of physical activity and active play for children}

There is compelling research evidence linking young people's engagement in physical activity with a range of positive health benefits (e.g. DoH, 2011). Indeed, Parker and Vinson (2013) note that participation in physical activity has been 'associated with having a positive impact on a range of personal conditions and characteristics, particularly where young people are concerned' (p.1). Moreover, others have argued that the scope of possible benefits is vast, with physical activity and movement having the potential to impact on all aspects of a child's development, including their physical, emotional, cognitive and social development (e.g. Bailey et al., 2009). Certainly, there is strong support for the health benefits that can accrue through participation in physical activity, with studies highlighting positive relationships between physical activity and, for example, muscular strength and endurance, flexibility, musculo-skeletal health, body composition and cardiovascular endurance (e.g. Biddle, Sallis \& Cavill, 1998; DoH, 2011). Moreover, research has also highlighted the cognitive and affective benefits that can accrue for young people, with studies noting improvements in concentration span, retention and academic performance (e.g. Sattelmair \& Ratey, 2009) as well as enhanced levels of motivation, self-confidence and general well-being (e.g. Malina, 2011). In addition, authors have pointed to the capacity for physical activity participation to contribute positively to young people's personal and social development, enhancing their acquisition of various 'life skills' (e.g. communication, leadership, teamwork, empathy etc.), nurturing social interaction and exchange and allowing them to develop resilience against difficult life circumstances (e.g. Holt, 2008; Armour, Sandford \& Duncombe, 2013). Just as there is strong support for the health benefits of physical activity participation for children, there is also a substantial body of research outlining the potential for play to improve all aspects of children's well-being: physical, emotional, social, and cognitive (BTHA, 2011). Perhaps unsurprisingly, there are many similarities in the perceived benefits highlighted in these bodies of work; particularly where the play is both unstructured and active. Burdette and Whitaker (2005), for example, have highlighted the importance of play for brain development and propose that there should be a strong focus on 'free play' for children, in order to enhance their health, development and well-being. Pellegrini and Smith (1998) note that 'children's play often has a vigorous physical component' and go on to suggest that such physically active play 
can 'matter psychologically' (p. 577) and have a significant impact on a child's understanding of rules, symbolic action and appropriate/acceptable behaviour.

\section{Concerns regarding the perceived decline in physical activity and active play}

However, despite the wealth of knowledge generated regarding the potential benefits of participation in physical activity for young people, there is also accumulating evidence that children are now less physically active than expected (Fisher et al., 2005) and that an increasing number of young people of primary school age are either overweight or obese (e.g. DoH, 2010). Moreover, some studies have proposed that this situation is compounded by a reduction in the amount of time children now engage in active play (e.g. Feda et al., 2012). Certainly, concerns have been expressed in recent times regarding a perceived decline in children's play, with some authors noting its effective relegation to the early childhood years and others highlighting the trend for play within schools to be targeted primarily at learning and the preparation for adult life (e.g. Play England/BTHA, 2011). Various studies have provided evidence to show that young people today are less likely to engage in active, outdoor play with their peers than the generations before them (Clements, 2004) and that children now have far fewer opportunities for self-directed play (e.g. McArdle, 2001; Gray, 2011). Various reasons have been given for this, such as heightened parental concerns over safety, a lack of available (safe) play spaces, increasingly sedentary lifestyles and the prohibition of various traditional childhood activities due to fears of litigation (e.g. Lacey, 2007; Thigpen, 2007). In addition, there would appear to be a growing perception that children should now be engaged in more 'productive' activity, particularly when they are in formal education contexts.

\section{The potential benefits of active play within the school context}

Certainly, the space for free play within primary schools appears to be restricting and this would appear to be an international trend. Studies from both the UK and US, for example, have noted a decline in the amount of time available for play during the school day (e.g. Blatchford \& Baines, 2006). Moreover, Beresin (2012) notes that there is also some evidence of this trend being replicated in other countries. The perceived need for a focus on 'productive activity' and to maximise the available time for learning in order to achieve educational 'targets' is seen to have played a key role in this process and led to a situation in which opportunities for children to engage in active play have been heavily reduced. Indeed, Kuschner (2012) has noted that 'much has been written about how children's play is under pressure from overly structured, academic curriculum and testing' (p.103). This is also reflected in the evident reduction in opportunities to play as children move through their school life (e.g. Wood, 2007). A recent report from the UK, for example, noted that children's free time at school decreased as they got older, with their total break times reducing from 91 minutes per day for 4-7 year olds, to 77 minutes for 7-11 year olds and just 69 minutes per day for 11-16 year olds (BTHA, 2011). Broadhead (2011) has also noted that by the time children are in Key Stage 1 (aged 5-7 years), activities related to literacy and numeracy strategies predominate and their teacher-led nature inhibits children's capacity to learn through play. Wood (2007) has argued, however, that such reductions in children's capacity to play within schools happens at a time when they are 'becoming master players' and that constraining opportunities to play in this way 'may deny its positive benefits, particularly in sustaining positive dispositions to learning' (p.311). 
Support for the learning-enhancing benefits of play is also provided by Trudeau and Shephard (2008), who showed in their study that when primary schools cut back on academic instruction in order to allow students more time for physical play, there was no subsequent decline in academic performance. Moreover, the associated social and physical benefits of active play have also been espoused in the literature in support for the inclusion of play opportunities within the school day (e.g. Panksepp, 2008; Fairclough et al., 2008).

It would seem, therefore, that there is much to gain from offering children opportunities to engage in active play during their school day. Bearing in mind the research outlining the increased engagement and activity of children when a variety of play equipment are offered (e.g. Play England/BTHA, 2011) it would seem that the nature and structure of play opportunities are important factors to consider with regard to this. Previous research has shown, for example, that modifying play features in a playground can increase children's physically active play (e.g. Hughes, 2007) and that children are more active when provided with a choice of active toys (Feda et al., 2012). The study outlined in this paper sought to add to this body of knowledge, through examining the impact of toys and toy substitutes on children's levels of physical activity within primary schools and comparing this to the levels of activity achieved during other supposedly 'active' periods of the school day. Moreover, through examining pupil perspectives of these play opportunities, it aimed to facilitate a more holistic understanding of children's active play.

\section{Methodological framework and data analysis}

The study outlined in this discussion sought to examine the impact of toys typically associated with active play (e.g. bicycles, footballs, scooters etc.) and toy substitutes (in this instance, 4 cardboard boxes of varying sizes) on children's levels of physical activity within primary schools, and to draw comparisons with their levels of physical activity in other typically 'active' periods of the school day: namely school breaks, lunch-times and physical education (PE) lessons. In addition, the research also sought to establish whether or not there was a difference in physical activity level when children played indoors or outdoors with the toys/toy substitutes. In total, 52 year 3 pupils (aged 7-8 years) from two different schools in the Midlands of England were recruited to be involved in the research project: 36 pupils from one school and 16 from the other, with an even number of boys and girls in each school. Prior to commencement of the fieldwork, consent was sought from the head teacher in each school and the parents/guardians of all participants, while pupils themselves were asked to indicate their assent before each session. Full ethical clearance for the research was provided by the research team's university.

In each of the schools, the children were allocated into groups of 4 by their teachers. The majority of these groups were single sex groups, but in each school there was one mixed group. Each group of children participated in one of following active play sessions (30 minutes duration) on four separate occasions:

- Indoors with a selection of cardboard boxes;

- Indoors with toys;

- Outdoors with a selection of cardboard boxes;

- Outdoors with toys. 
Each group undertook their sessions at the same time on each of the four days. A full inventory of the toys available in the indoor and outdoor sessions is provided in Table 1. The children were given a standard set of instructions at the start of each session, but these focused primarily on safety issues and provided minimal information about what was expected of them during the 30 minute play session.

As noted earlier, a multi-method research design, focussed on the generation of both qualitative and quantitative data, was employed in this study, in order to more accurately explore the holistic impact of the active play sessions on the young participants (e.g. Patton, 2002). The data collection process has been outlined in detail elsewhere (see Morris et al., 2012) but, in summary, quantitative data were generated primarily via the use of accelerometers and heart rate monitors, which monitored the children's physical activity levels during the duration of the school day in which the active play sessions occurred. The research team also recorded the times that the children were in the classroom, had break/lunch- times or took part in PE lessons. Each of the play sessions was video-recorded and an observer noted down specifics about the session e.g. date/time as well as general comments about the session (e.g. weather conditions, group dynamics, popular/unpopular toys). Every five minutes during the session, a 'snapshot' was taken of what the children were doing so that more descriptive explanations could be included in the analysis. Following the completion of all four active play sessions, additional qualitative data were generated through semi-structured focus groups, conducted approximately one month after the children had completed the study. Focus group questions sought to clarify queries arising from the researchers' observations and also to explore the children's experiences of the four active play sessions. For example, pupils were asked, among other things, to reflect on the sessions, consider the elements of sessions they enjoyed most/least and give their opinions about the location of the sessions as well as the types of play equipment available to them. In this way, the research approach both acknowledged the contemporary perception of young people as capable of reflecting on, understanding and articulating their own experiences (e.g. Christensen \& James, 2008) and heeded calls within the literature for a greater allowance for and inclusion of youth voices within research endeavours (e.g. O’Sullivan \& MacPhail, 2010).

In terms of data analysis, the quantitative data were downloaded from each accelerometer daily and processed using the ActiGraph Analysis Tool, which enabled calculation of the average time that children spent in different physical activity intensities during the recording period (see Morris et al., 2012). The qualitative data, generated through the observations and focus group discussions, were analysed thematically using an approach akin to the grounded theory process outlined by Charmaz (2000) and Harry, Sturges and Klingner (2005). In brief, the raw data (observation notes, video recordings and interview transcripts) were read and reviewed a number of times by multiple members of the research team, facilitating both an understanding of and familiarity with the collated information. During this process, the data also underwent a process of repeat coding and categorisation, in order to identify key issues and gradually reveal core themes for discussion. Cross-checking and drawing comparisons between these different sources of information, also served to aid the process of triangulation of the data and, as 
Altrichter, Feldman, Posch and Somekh (2008) have noted, thereby give a more balanced picture of the research situation. The main findings from the data analysis are presented below.

\section{Results}

This analysis focuses on the qualitative data generated through the study. A full discussion of the quantitative findings can be found in Morris et al., (2012), but a broad overview of some key findings is now given to provide some context for the subsequent thematic analysis. In terms of physical activity levels, the study revealed that the children were, in general, more active in the play sessions than they were at other times in the school day (specifically, break times, lunch times and PE lessons). The results also indicated that boys were slightly more active than girls in the play sessions and that pupils tended to be less active in indoor toy sessions than outdoor sessions. Interestingly, the data would seem to suggest that relatively short sessions of active play with toys (or some sort of toy substitute) can make a potentially important contribution to the total quantity of physical activity undertaken by children in schools.

The qualitative data (i.e. the observations, video analysis and focus groups) shed further light on the quantitative findings and help to provide valuable context as well as offer plausible explanations for the quantitative data. A number of qualitative themes were identified through the analysis process, highlighting issues such as the relevance of equipment, context and group dynamics to the pupils' experiences etc., but for the purposes of this discussion, two interrelated themes are highlighted as being particularly pertinent: the pupils' general enjoyment of the play sessions and the significance of a child's creative, social and physical competence during play. It was evident that these themes have significant potential to act as both a barrier and a facilitator to children's play and, consequently, have an impact on young people's physical activity levels as well as their personal and social development in and through play.

\section{Theme 1: Enjoyment of the play sessions}

The observations, video analysis and focus groups all confirmed that the pupils largely enjoyed their involvement in the study. For example, the pupils referred to the project as having been, among other things, 'fun', 'amazing' and 'supertastic'. Indeed, they were always keen to attend the play sessions and when the focus groups were conducted four weeks later, the majority of pupils were still very enthusiastic about the study and many asked to repeat it. For example:

\section{'I'd give it 1 million out of 100, it was the best time ever' (Boy, School A)}

\section{'If I could have another week with you that would be fantastic' (Girl, School A)}

In addition, it was clear that many pupils appreciated the additional opportunity for unstructured play during the school day, giving respite from the directed 'work' of lessons and providing a chance to get more time out of the classroom with their friends. For example, one girl from School A noted, 'we just normally do boring old work and (the project) was something good', while one of her male peers commented that the outdoor sessions allowed them to 'get fresh air (because) you get boiling inside'. Moreover, the potential to engage in 
new/novel activities with various types of equipment (both toys and boxes) was a source of enjoyment and motivation for many individuals. Indeed, for some, the enjoyment of the sessions was largely determined by the ability to 'do something different' and have a break from the norm. For example, when explaining why he felt that playing with the boxes had been more fun than the toys, one boy (School A) commented that 'I always play with toys and (although) I have played with cardboard boxes before, it's not been for a long time'.

Interestingly, the responses from pupils were similar regardless of which type of group they were in (i.e. mixed or single sex), suggesting that gender was not necessarily a key influence in their enjoyment. Moreover, when asked in the focus groups about the influence of gender grouping on their experiences of the play sessions, there were remarkable similarities in pupils' responses. For example, while there were some suggestions from pupils in single sex groups that being with peers of the same gender enhanced their satisfaction of the play sessions ('I wouldn't have liked it as much if there had been girls in the group, I just prefer playing with only boys'; 'I liked it with just girls, because girls are different to boys'), those in the mixed groups also felt there were benefits to having pupils of both genders ('I think having boys and girls together was better'; 'It was good having boys and girls together because it was fair and we had teams').

\section{Theme 2: Creative, social and physical competence during play sessions}

It was clear that the children's competence to play influenced, to varying degrees, their engagement in the sessions. More specifically, their physical, creative and social competence, i.e. their ability to play with the toys/toy substitutes on offer, their ability to use their creativity to enhance their play and their ability to play with others, were key factors in shaping the nature and extent of their engagement. Certainly, physical competence impacted the ways in which the children played with the toys and, in turn, affected their activity levels. For example, while some of the children were skilled in using the bicycles or scooters, other children were not and this necessarily impacted on the ways in which they played with these toys. As one boy (School B) was observed commenting in a play session, 'how do you actually ride a skateboard?'. Likewise, there were toys which required additional input (e.g. because they were novel to the children or required instructions for use) and the children often avoided these or moved on from them if they could not master them quickly. The following extracts, taken from observation notes of play sessions, provide some illustrative examples:

One of the girls tried the bike and was overheard saying, 'I can't do anything. I'm not good at anything'. She then sat out at the side and explained to one of the researchers that she still had the stabilisers on her bike at home (Mixed group, outdoors with toys, School B)

One of the boys was noted as being very active and quite skilled at using the equipment. For example, he seemed to have used a skateboard before and he also spent a short while cycling very fast in and out of the cones (Mixed group, outdoors with toys, School B). 
Creative competence was also an important element of the children's active play. The boxes proved to be a popular stimulus for creativity and many of the children enjoyed playing with the boxes far more than was initially anticipated. In general, the children either played very creatively or very destructively and in some sessions, they would play creatively having been destructive (i.e. after destroying the boxes). The smallest box, for example, was used, among other things, as a hat, a football and a jewellery box, whilst the larger boxes were often used as houses, dens, forts or vehicles (e.g. cars, boats). The remnants of the boxes were also put to good use and became 'wings' so that the children could be birds/aeroplanes or they were worn as items of clothing or made into pretend weapons (e.g. guns, swords). However, the need to be creative was also problematic for some pupils, as the following quote illustrates:

'...with boxes you can't be very active because you have to imagine (and) I'm not very good at imagining things' (Girl, School A)

The toys also provided a stimulus for creative play for some pupils. For example, when faced with toys that they were unfamiliar with, children often invented new ways of playing that enabled them to use them, for example: kneeling on the skateboard and using feet to move along; using the skipping rope to pull others on the skateboard; and filling the tunnel up with toys. As the following extract from a session observation indicates:

At the end of the session, three of the children decide to use the skipping rope to pull each other along on the skateboard and this activity caused great excitement and shouts of 'faster, faster!' (Mixed group, outdoor with toys, School B).

Finally, social competence was important in determining both the type and intensity of the children's activity. Some groups had clear 'leaders' who would initiate or lead activities, inviting others to play and determining the nature of participation. These individuals were often those with good communication skills or high levels of physical competence, but it was also evident that self-confidence and social status within the peer group played an important role here. For example, in the mixed group in School B, Noah was identified by the session observer as a 'leader' and his actions were often central in initiating, directing or encouraging participation in activities. As the following extracts from observation notes recorded during one session demonstrate:

'Noah's got good imagination and makes contact with other members of the group... Noah knocks on Stacey's door, (he) lifts up box - which upsets her...Noah takes box over to Stacey and says it's an apology and they are going to make something nice... Noah starts putting on a show - others look confused but start to follow his lead' (Mixed group, outdoor with toys, School B).

In other groups there was more of a balance in pupils' input or participation, with children playing together as a collective or in pairs. However, there were also examples of some children lacking social competence and finding it hard to join in with the activities of the 
group. In such instances, these children were observed sitting or playing on their own and, occasionally, their requests to join in were ignored or declined. As the following extract from an observation session in School A indicates:

'3 girls play together (they) use some space but don't use whole area...1 girl (Amy) plays on her own - she doesn't use much space - (and) spends most of the session talking to the observers... Very little interaction between the 3 girls and Amy...some animosity when Amy asks if she can play' (Girls group, outdoor with boxes, School A).

Interestingly, with regard to the issue of competence, there were few differences with regard to gender. While there was some reproduction of conventional views of gendered play by pupils in the focus groups (i.e. boys as physical, competitive and destructive and girls as more passive, collaborative and creative) there was no clear distinction between boys and girls in terms of their physical, social or creative competence in the play sessions themselves. These findings, along with those others cited here, are explored further in the following section, with reference to relevant literature in the field and with the intention of identifying implications for future research, policy and practice in this area.

\section{Discussion}

The data presented here can be seen to demonstrate the potential of toys and toy substitutes to impact the physical activity levels of children and to enhance enjoyment of play sessions within the school environment. However, it is also evident that various additional factors impact young people's play experiences and influence the nature and extent of their engagements, not least their physical, creative and social competence. In this respect, the study can be seen to reinforce the findings of other research in the field that has pointed to the significance of ability and competence in relation to young people's participation in physical activities (e.g. Clark, 2012) as well as the importance of enjoyment and fun (e.g. Hemming, 2007). This study has indicated that providing young children with space, time and an opportunity to play (as well as equipment to play with) within the school day can be beneficial in terms of enhancing enjoyment and increasing their levels of physical activity. This would seem to reinforce an existing body of literature that points to the importance of space, equipment and opportunity in facilitating children's active play (e.g. Feda et al., 2012). Cardon, Labarque, Smits and Bourdeaudhuij (2009), however, caution against too much hope being placed on the provision of equipment, noting the possible reduction of positive effects once the novelty of new things has worn off. Nonetheless, the finding regarding the importance of providing play opportunities is pertinent, especially in an age where the perceived importance of such opportunities is recognised but acknowledged as being in decline (Gray, 2011) and the focus on 'academic' achievement is at a high (Kuschner, 2012). The case for increasing physical activity and opportunities to play has already been made, not least because engagement in both has been linked to improvements in health, well-being and personal/social development (e.g. Burdette \& Whitaker, 2005; DoH, 2011; Bailey et al., 2009). Certainly, the 
pupils in this study both appreciated additional opportunities to play within the school day and enjoyed the unstructured nature of this activity. Such findings can be seen to reinforce additional studies in the field, such as those of Roemmich, Lambiase, McCarthy, Feda and Kozlowski (2012) in which the significance of activity choice and autonomy over play decisions is highlighted, and Gray (2011) who argues that children still appear to prefer outdoor play with friends over other forms of play context. Moreover, importantly, an indirect result of the pupils' enthusiasm in this study was an apparent increase in physical activity. Previous research has established the role that enjoyment can play in motivating young people to be active, with Hemming (2007), for example, finding that children were motivated more by 'fun' activities than by 'healthy' activities.

As demonstrated in the previous section, data from the observations were especially helpful in illustrating some of the complex ways in which the pupils played and also highlighted a number of 'competencies' that acted as facilitators of or barriers to children's physical activity during play sessions. Certainly, the analysis of the qualitative data identified three key elements in this regard: social competence, physical competence and creative competence. Those children who were competent in any or all of these areas tended to be able to engage in more productive play (i.e. focussed and purposeful), which, in turn, led to increased physical activity on their part. Goldstein (2003) has described such capacities as 'play competencies' and the data outlined here would appear to support their importance for children's capacity to be physically active through unstructured play. For example, as noted, a number of children in this study were observed struggling to use some of the toys because of a lack of physical skill and this led to frustration and the toy being discarded or the child sitting out for part of the session. In instances such as this, the child's physical competence was arguably low; however, some children were able to use their creative competence to overcome this, creating novel or inventive ways to play. Research from the field of physical education around physical literacy (Whitehead, 2010) and fundamental movement skills (Jess et al., 2004) can also be seen to have relevance here, with authors arguing that an individual's capacity and desire to participate in physical activities (across the life course) is bound up with the development of confidence, knowledge and understanding regarding their movement competencies. It would certainly seem, therefore, that interventions to improve any or all of these 'play competencies' could potentially enhance the quality of play, the developmental outcomes of play sessions and a child's ability to be physically active through play.

An interesting finding of this study is that engagement in active play appeared to be strongly influenced by the pupils' social skills and capacity to engage, communicate and share ideas with their peers. A number of situations occurred, for example, where a child perceived (by the researchers) to have high social competence would invite another child to play with them and this often facilitated or extended an episode of play. Conversely, other children struggled to engage with their peers and tended to drift to the periphery of an activity. Other studies have also highlighted the significance of the social aspect of children's play, pointing to the capacity for individual's to gain social status (Feda et al., 2012), accumulate physical capital (Sandford \& Rich, 2006) and develop valuable life skills (Gray, 2011) through physically active play. Certainly, Kangas, Uusiautti and Määttä (2012) argue that 
communication and social interaction skills are important for young children, facilitating their capacity to enter into and engage in play contexts, while Goldstein (2003) has noted the potential for positive transfer of pro-social skills from play contexts to the classroom. In this way, it is perhaps easy to see how physically active play has come to be viewed as an important 'social conduit' (BTHA, 2011 p.9) for children and a necessary part of young people's 'social diet' while at school (Panksepp, 2008 p.55). While such a focus on social interaction in play has many positives, however, it is worth noting that concerns have also been expressed regarding an overtly 'adult-centric' perspective in this. Lester and Russell (2013), for example, have argued that an understanding of play as a means of developing social capital is now embedded in UK policy as part of a neoliberal agenda, but also talk of the need to avoid the 'adulteration' of play contexts, i.e. 'the persistent and increasing incursions of adult rationality and control into places where children play' (p.49). Moreover, they articulate something of the challenge facing contemporary play workers in creating unsupervised/unstructured play spaces, while also ensuring that the play itself remains meaningful, purposeful and comprises opportunities for personal, social and physical development.

An additional point to note stems from the finding that cardboard boxes were as successful in promoting opportunities to be active for the pupils as the toys (and equally engaging). This finding was initially surprising, but the analysis of the qualitative data would seem to suggest that, given the opportunity to be creative, children will play with objects that are not specifically designed to be active toys. For example, the observations revealed that there were numerous ways in which the boxes were played with (over 50 different uses were noted) and the focus groups with pupils highlighted, among other things, that the boxes were perceived to be interesting because they were novel and that the variable uses of the boxes facilitated the creation of enjoyable and engaging make-believe games. Moreover, the group discussions revealed that pupils clearly appreciated the fact that the boxes could be played with in ways that were not structured or constrained by adults (as noted, the children were given no guidance from the researchers in this respect). This links to the issue highlighted above concerning the role of adults in children's play and once again points to the need for a balance to be struck between adult guidance and adult direction of play contexts (e.g. Lester \& Russell, 2013). It should be noted, however, that while the pupils played equally actively with the boxes and the toys, at the end of the play sessions it was generally only the toys that remained intact; the boxes were almost invariably destroyed and were therefore not able to be re-used within subsequent play episodes. Finally, it is worth noting that while gender was found to have some influence on pupils' engagements with/use of the toys and boxes, it did not appear to play a significant role in this study. Indeed, the pupils' responses would suggest that, at this age, gender differences are more apparent in theory (i.e. in the perceptions of how boys and girls should play) than in practice. This is perhaps an interesting avenue for future research.

The above discussion identifies a number of barriers and facilitators to children's play and perhaps allows for tentative recommendations to be made for policy makers, play professionals or parents wishing to increase physically active play opportunities for children. In particular, the data would seem to suggest that adult intervention and input is sometimes required, in order to facilitate and encourage play. As Goldstein (2003) has noted, children 
need supportive adults, adequate play space and suitable play equipment in order to gain maximum benefit from play. Thus, had some of the pupils in this study been shown how to use some of the toys (the bike and pogo stick, for example) and been given support/guidance as and when it was needed, they may have been able to engage more successfully with them. Another aspect of this would be the need for adults to not only show the young people how the toys worked, but also to help them to develop competence and confidence when using them. It is argued that such adult input, or indeed peer support, may facilitate play and, hence, opportunities to be active (e.g. Jess, Dewar \& Fraser, 2004). However, whilst adult input and support would clearly have been helpful, the data from this study illustrate the ways in which young people, when faced with a toy that they could not use, would devise a new way to play with a toy. Thus, a balance between facilitating play to avoid frustration and disengagement, and allowing young people to be creative and inventive with unfamiliar equipment, clearly needs to be struck.

\section{Conclusion}

The aim of this discussion has been to present key findings from an innovative mixedmethod study that primarily sought to determine the impact of toys and toy substitutes on children's physical activity levels. It has been shown that the study play sessions did indeed have a positive impact on the physical activity levels of the pupils and, moreover, that the provision of play equipment (whether designed for active play or not) and space/time in the school day for play, had the potential to enhance pupils' enjoyment of/engagement in active play. However, it was also noted that children's levels of physical, creative and social competence played a significant role in influencing the nature and extent of their engagement in active play. It is argued that there are a number of important implications emanating from this study. Firstly, that young people should be provided with more opportunities to play both at school and at home as one way of increasing their physical activity; secondly that adult input may be beneficial in such situations (as long as it isn't intrusive to the degree that it stifles creativity); thirdly that increasing a child's competence, specifically in the domains of creativity, social skills and/or physical ability, may enable a child to engage in more successful and active play; and, finally, that toy substitutes have just as much capacity to facilitate physically active play as active play equipment (although they may have less longevity). Moreover, it is clear that additional research is needed in this area, in order to further explore issues identified through this study. In particular, there perhaps needs to be more focus on: the role of adults within play environments; the development/evaluation of interventions intended to facilitate children's social skills, physical competence and creativity; and the nature/value of active play in different contexts and with different cohorts of young people (e.g. in preschool settings, observing gender differences; and with children with special educational needs). In addition, future research could also usefully look at how issues of competence and engagement in play are talked about by children themselves during their play activity, through closer analysis of the recorded social interactions (see Butler et al., under review). This could, potentially, offer a rich account of how children collaboratively produce and organise play activity (Butler, 2008). The data presented above would certainly lend credence to the argument that unstructured active play in children's free time can contribute to young people's total daily physical activity levels (Brockman et al., 2010). Moreover, the insight gained through the 
mixed-method approach points to the value of undertaking a more holistic approach to the study of young children's active play. Indeed, Vinson and Lloyd (2013) argue that the adoption of more holistic pedagogic practices is necessary, certainly by practitioners within the field of physical education and school sport, if young people's capacity to engage in/develop through physical activity and active play is to be enhanced.

\section{Acknowledgements}

The authors gratefully acknowledge the support of the British Toy and Hobby Association who funded the project and have encouraged the dissemination of project findings. In addition, we would like to recognise the invaluable contribution made by colleagues from the Institute of Youth Sport at Loughborough University, namely: Dr. Mary Nevill, Dr. John Morris, Dr. Trish Gorely, Susie Brown, Gail Matthews, Hayley Musson, Cathie Taylor, Sophie Hobson and James Dorling. Finally, we express our gratitude to the pupils and staff of the two project schools for their participation in the study. 


\section{References}

Altrichter, H., Feldman, A., Posch, P. \& Somekh, B. (2008). Teachers investigate their work: An introduction to action research across the professions (second edition). New York: Routledge.

Armour, K.M., Sandford, R.A., \& Duncombe, R. (2013). Positive youth development and physical activity/sport interventions: Mechanisms leading to sustained impact, Physical Education \& Sport Pedagogy, 18(3), 256-281.

Bailey, R., Armour, K., Kirk, D., Jess, M., Pickup, I., \& Sandford, R. (2009) The educational benefits claimed for physical education and school sport: an academic review, Research Papers in Education, 24(1), 1-27.

Beresin, A. R. (2012). Play Counts: Pedometers and the case for recess. International Journal of Play, 1(2), 131-138.

Biddle, S., Sallis, J.F. \& Cavill, N. (Eds) (1998). Young and active? Young people and health-enhancing physical activity: Evidence and implications. London: Health Education Authority.

Blatchford, P. \& Baines, E. (2006). A follow up national survey of breaktimes in primary and secondary schools: Reported to Nuffield Foundation. Available online from: http://www.breaktime.org.uk/NuffieldBreakTimeReport-WEBVersion.pdf (Accessed Nov. 2011).

British Toy and Hobby Association (2011). Active play and healthy development. Available online at: http://www.btha.co.uk/consumers/template.php?id=169 (Accessed Nov. 2011).

Broadhead, P. (2011). Developing an understanding of young children's learning through play: The place of observation, interaction and reflection. British Education Research Journal, 32(2), 191-207.

Brockman, R., Jago, R. \& Fox, K. R. (2010). The contribution of active play to the physical activity of primary school children. Preventive Medicine, 51, 144-157.

Burdette, H.L. \& Whitaker, R.C. (2005). Resurrecting free play in young children: Looking beyond fitness and fatness to attention, affiliation, and affect. Archives of Pediatric and Adolescence Medicine, 159(1), 46-50.

Butler, C.W. (2008). Talk and social interaction in the playground. Aldershot: Ashgate.

Butler, C.W., Duncombe, R., Mason, C. \& Sandford, R. (under review) Recruitments, engagements and partitions: Managing participation in play. Paper submitted for review to the International Journal of Play. 
Cardon, G., Labarque, V., Smits, D. \& Bourdeaudhuij, I. (2009). Promoting physical activity at the pre-school playground: The effects of providing markings and play equipment. Preventive Medicine, 48, 335-340.

Charmaz, K. (2000). Grounded theory: Objectivist and constructionist methods. In N.K. Denzin \& Y.S. Lincoln (Eds.), Handbook of qualitative research, 2nd edition (pp. 509-536). London: Sage.

Christensen, P. \& James, A. (2008). Research with children: Perspectives and practices (second edition). London: Routledge.

Clark, S. (2012). Being 'good at sport': Talent, ability and young women's sporting participation. Sociology, 46(6), 1178-1193.

Clements, R. (2004). An investigation of the status of outdoor play. Contemporary Issues in Early Childhood, 5(1), 68-80.

Department of Health (2010). Healthy lives, Healthy people: Our strategy for public health in England. London: TSO.

Department of Health (2011). Start active, stay active: A report on physical activity from the four home countries' Chief Medical Officers. London: DoH.

Fairclough, S, Butchers, Z \& Stratton, G (2008). Primary school children's health-enhancing physical activity patterns: The school as a significant environment? Education 3-13, 36(4), 371-81.

Feda, D. M., Lambiase, M. J., McCarthy, T. F., Barkley, J. E. \& Roemmich, J. N. (2012), Effect of increasing the choice of active options on children's physically active play. Journal of Science and Medicine in Sport, 15(4), 334-340.

Fisher, A., Reilly, J.J., Kelly, L.A., Montgomery, C., Williamson, A., Paton, J.Y. \& Grant, S. (2005). Fundamental movement skills and habitual physical activity in young children.

Medicine \& Science in Sport \& Exercise, 37(4), 684-688.

Goldstein, J. (2003). Contributions of play and toys to child development: Key studies. Report developed for the Toy Industries of Europe.

Gray, P. (2011). The decline of play and the rise of psychopathology in children and adolescents. American Journal of Play, 3(4), 443-463.

Harry, B., K.M. Sturges, \& J.K. Klingner (2005). Mapping the process: An exemplar of process and challenge in grounded theory analysis. Educational Researcher, 34(2), 3-13.

Hemming, P. J. (2007). Renegotiating the primary school: Children's emotional geographies of sport, exercise and active play. Children's Geographies, 5(4), 353-371.

Holt, N.L. (2008). Positive youth development through sport. London: Routledge. 
Hughes, B (2007). Does adventure playground modification affect the intensity of the play that takes place there? Playrights Magazine, 2, 19-22.

Jess, M., Dewar, K. \& Fraser, G., (2004). Basic Moves: Developing a foundation for lifelong physical activity. British Journal of Teaching in Physical Education, 35(2), 23-27.

Kangas, S., Uusiautti, S. \& Määttä, K. (2011). Social interaction among children with Autism Spectrum Disorders (ASD). International Journal of Early Childhood Special Education, $3(2), 160-174$.

Kuschner, D. (2012). What is the state of play? International Journal of Play, 1(1), 103-104.

Lacey, L. (2007). Street play: A literature review. London: National Children's Bureau.

Lester, S. \& Russell, W. (2013). Utopian visions of childhood and play in English social policy. In, A. Parker \& D. Vinson (Eds.), Youth sport, physical activity and play (pp. 40-52). London: Routledge.

Malina, R.M. (2011). The health of young athletes. In, I. Stafford (Ed.) Coaching children in sport (pp.240-253). London, Routledge.

McArdle, Paul. (2001). Children's play. Child: Care, health and development, 27, 506-514.

Morris, J., Mason, C., Sandford, R., Duncombe, R. Gorely, T., Hobson, S., ...Nevill, M. (2012). Examining the impact of toys on children's physical activity: Final report.

Loughborough: Institute of Youth Sport.

O’Sullivan, M. \& MacPhail, A. (Eds) (2010). Young people's voices in physical education and sport. London: Routledge.

Panksepp, J. (2008). Play, ADHD, and the construction of the social brain. American Journal of Play, 1(1), 55- 79.

Parker, A. \& Vinson, D. (2013). Introduction: Youth sport, physical activity and play. In, A. Parker \& D. Vinson (Eds.), Youth sport, physical activity and play (pp. 1-9). London:

Routledge.

Patton, M.Q. (2002). Qualitative research and evaluation methods, 3rd Edition. London: Sage Publications.

Pellegrini, A.D. \& Smith, P.K. (1998). Physical activity play: The nature and function of a neglected aspect of playing. Child Development, 69, 577-598.

Play England/BTHA (2011) A world without play: A literature review. London: Play England and the British Toy and Hobby Association.

Roemmich, J., Lambiase, M., McCarthy, T., Feda, D. \& Koslowski, K. (2012). Autonomy supportive environments and mastery as basic factors to motivate physical activity in 
children: a controlled laboratory study. International Journal of Behavioral Nutrition and Physical Activity, 9, 16.

Sandford, R.A. \& Rich, E.J. (2006). Learners and popular culture. In, D. Kirk, M. O'Sullivan \& D. Macdonald (Eds.), Handbook of research in physical education. London: Sage.

Sattelmair, J. \& Ratey, J. J. (2009). Physically active play and cognition: An academic matter? American Journal of Play, 1(3), 365-374.

Thigpen, B. (2007). Outdoor play: Combating sedentary lifestyles. Zero to Three, 1, 19-23.

Trudeau, F. \& Shephard, R.J. (2008). Physical education, school physical activity, school sports and academic performance. International Journal of Behavioural Nutrition and Physical Activity, 5, 10.

Vinson, D. \& Lloyd, M. (2013). Moving forward from the Physical Education, School Sport and Young People Strategy. In, A. Parker \& D. Vinson (Eds.), Youth sport, physical activity and play (pp. 126-137). London: Routledge.

Whitehead, M. (Ed.) (2010). Physical literacy through the life course. London: Routledge.

Wood, E. (2007). New directions in play: Consensus or collision. Education 3-13.

International Journal of Primary, Elementary and Early Years Education, 35(4), 309-320. 


\section{Tables}

\begin{tabular}{|l|l|}
\hline \multicolumn{1}{|c|}{ Indoor Toys } & \multicolumn{1}{|c|}{ Outdoor Toys } \\
\hline Table tennis set & Scooter \\
Football training mat & Skateboard \\
Hide \& seek tunnel & Skipping rope \\
Indoor boomerang & Bike \\
Bowls & Frisbee \\
Space hopper & Football \\
Hula hoop & Cricket bat \& ball \\
Sticky pad and balls & Space hopper \\
Dance mat & Small trampoline \\
Air hockey table & Pogo stick \\
\hline
\end{tabular}

Table 1: List of toys available in the indoor and outdoor play sessions 